\title{
LEGITIMIDAD PARA OBRAR
}

Fausto Viale Salazar

\section{Nociones previas}

Mucho se ha escrito y diversas posiciones han surgido en la doctrina acerca del concepto de acción. No es de extrañar, incluso entre autores de corriente cercana de pensamiento, que puntualicen sus propios matices al concebir la acción, lo que nos coloca frente a un enmarañado panorama.

Lo que sí resulta incuestionable e irreversible, es el salto cualitativo que significó la famosa polémica Windscheid-Müther (1856-1857) que condujo a la autonomía del derecho de acción frente al derecho subjetivo material. Estos acontecimientos llevarán al deslinde científico entre Derecho Procesal y Derecho Civil (derecho material), y su tratamiento como disciplinas jurídicas autónomas aunque interconectadas. A partir de entonces no será más concebible tratar el aspecto procesal como mero apéndice o accesorio del derecho material, como lo hacían las viejas doctrinas de Savigny, Planiol, y escasísimas posiciones modernas como la de Satta, entre otros.

Los primeros deslindes de Windscheid se efectuarán a partir de la distinción entre los conceptos de acción y pretensión (anspruch), concibiendo a la acción como el poder de hacer valer en juicio una pretensión ${ }^{1}$. Se deberá a Müther el desplazamiento del tratamiento de la acción hacia el derecho público al considerarla no ya como un derecho subjetivo privado, sino como

1 Clariá Olmedo, Jorge A., Derecho procesal, Ediciones Depalma, Buenos Aires, 1982, t. I, pág. 288 . 
un derecho subjetivo público, en tanto que la actividad del accionante se dirige hacia el Estado, quien a través de los órganos jurisdiccionales tiene el deber de prestar la tutela jurisdiccional que pretenden los ciudadanos, mediante la garantía de un adecuado proceso.

Desde la aparición de las tesis de Windscheid y Müther surgirán eminentes autores que irán elaborando y reelaborando científicamente los principales conceptos procesales. Wach y Chiovenda, serán connotados exponentes de una direccion que se ha dado en llamar corriente concreta, para la cual la acción se concibe como un derecho del individuo frente al Estado a fin de obtener la tutela jurídica de sus derechos. De acuerdo a esta corriente no habrá derecho de acción si el derecho cuya tutela se pretende no existe. O sea, sólo quien tiene razón, tendrá derecho de acción.

La corriente concreta, como se podrá advertir, no llegó a lograr una total autonomía conceptual de la acción frente al derecho material.

La corriente concreta va a evolucionar hacia la denominada corriente abstracta, a partir de la teoría expuesta por Degenkolb. Esta corriente es hoy día la más aceptada y reconoce como objeto del derecho de acción simplemente a la actividad jurisdiccional, cualquiera sea su resultado, favorable o adverso a quien ha desencadenado la actividad jurisdiccional ${ }^{2}$. Llegamos así, finalmente, a una verdadera concepción autónoma del derecho de acción como el derecho a la tutela jurisdiccional efectiva. No se quiere expresar con el término abstracto que la acción sea en sí misma abstracta, sino que la existencia de la acción no atiende a que el titular del poder de acción tenga o no tenga razón ${ }^{3}$.

Ahora bien, esto no significa que la tutela que se pretenda deba ser afirmada en la demanda sobre un marco de hechos sin relevancia jurídica. Como bien lo señala Clariá Olmedo, al formular la pretensión debe existir un fundamento consistente en afirmaciones de hecho jurídicamente relevantes, lo que le da el carácter de jurídica a la pretensión. La expresión «relevancia jurídica» debe ser entendida como el encuadramiento de los he-

2 Montero Aroca, Juan; Manuel Ortells Ramos, y Juan Luis Gómez Colomer, Derecho jurisdiccional, Librería Bosch, Barcelona, 1989, t. I, pág. 403.

3 Clarí́ Olmedo, op. cit, t. I, pag. 292. 
chos afirmados (y por ello sólo posibles para el juzgador) en cualquier esquema normativo del ordenamiento jurídico constituido. Los hechos suelen consistir en acontecimientos, conductas, estados, relaciones y situaciones, tanto positivas como negativas, que el demandante alega al presentar la pretensión, y en virtud de los cuales postula, sosteniendo su concordancia con el esquema fáctico hipotizado en la norma jurídica que invoca como tuteladora de su interés ${ }^{4}$.

La corriente abstracta la encontramos recogida por el artículo I del Título Preliminar del Código Procesal Civil, cuando señala que «toda persona tiene derecho a la tutela jurisdiccional efectiva para el ejercicio o defensa de sus derechos o intereses, con sujeción a un debido proceso».

Es necesario tener en cuenta estas nociones previas para plantear en sus términos correctos la figura de la legitimidad para obrar.

\section{Concepto}

Nuestro Código Procesal Civil no define la legitimidad para obrar, pero continuamente hace referencia a ella.

La legitimidad para obrar está referida a los sujetos a quienes, ya sea en la posición de demandantes o de demandados, la ley autoriza a formular una pretensión determinada o a contradecirla, o a ser llamados al proceso para hacer posible una declaración de certeza eficaz o a intervenir en el proceso por asistirles un interés en su resultado.

La legitimidad para obrar tiene dos aspectos: la legitimidad activa y la legitimidad pasiva, que corresponde, la una, a la parte que sostiene la pretensión, y la otra, a la parte contradictora. Mención especial merece la legitimidad para la intervención de terceros por sus particulares características, aunque en la mayoría de los casos los terceros terminen integrándose en la legitimidad activa o pasiva.

La legitimidad para obrar tiene una definitiva vinculación con la rela-

4 Clariá Olmedo, op. cit., t. I, pág. 300. 
ción jurídica de derecho material o estado jurídico cuya declaración de certeza, ejecución, u otro tipo de providencia judicial se pretende. Como lo anota Véscovi, la legitimidad para obrar se refiere a la posición de un sujeto respecto al objeto litigioso que le permite obtener una providencia eficaz. Aunque es un concepto procesal, la legitimidad está referida a la pretensión y al objeto del proceso, esto es, al derecho sustancial reclamado 5 .

Rocco precisa que las normas sobre legitimidad para obrar constituyen un concepto sistemático de reglas procesales concernientes a la posibilidad o licitud jurídica de accionar (sic), para lo que es necesario recurrir a criterios fijos y constantes, en virtud de los cuales deban ser determinados los sujetos titulares del derecho de accionar (sic) y de contradecir. Agrega que «tales criterios tienen que constituir un conjunto orgánico de reglas que sirvan para establecer qué sujetos pueden hacerse actores en juicio, formulando la demanda judicial, esto es, a qué sujetos les es jurídicamente lícito pretender la prestación de la actividad jurisdiccional, y por consiguiente, les es jurídicamente posible formular la demanda judicial, con la cual piden una determinada providencia jurisdiccional, frente a otro u otros determinados sujetos... aquí hablamos de una licitud y de una posibilidad jurídica, no de una mera posibilidad o licitud de hecho» ${ }^{6}$.

Dada la referencia que tiene la legitimidad para obrar a quienes la ley autoriza a solicitar la actividad jurisdiccional en resguardo de determinados derechos de tipo material, y a quien debe dirigirse la pretensión, un sector de la doctrina ha confundido la legitimidad bajo estudio con la titularidad misma del derecho material de quien se presenta ante los estrados judiciales para reclamar la tutela de sus derechos, y la posición del demandado con quien igualmente es parte de la relación jurídica material. Así, para esta posición, sólo el comprador y el vendedor se encontrarán legitimados para obrar en un conflicto derivado de un contrato de compraventa.

Si pretendemos ser consecuentes con una posición estrictamente procesal de la legitimidad para obrar, no podemos admitir esta postura. En

5 VÉsCovi, Enrique, Teoria general del proceso, Editorial Temis Librería, Bogotá, 1984, pág. 196.

6 Rocco, Ugo, Tratado de Derecho procesal civil, Temis - Depalma, Bogotá Buenos Aires, 1976, vol. I, págs. 351 y 352. 
efecto, dentro de una posición que resulte coherente con la corriente abstracta de la acción o de la tutela efectiva, tendremos que concluir que para que se cumpla con la legitimidad para obrar, bastará la afirmación de la existencia de la posición autorizada por la ley. De otra manera, estaremos invadiendo el ámbito de la determinación de la existencia o inexistencia del derecho material. (Ver punto $4 .^{\circ}$.)

\section{Denominación}

En la doctrina la denominación más extendida es la de legitimatio ad causam o legitimación en la causa.

Chiovenda mostraba su preferencia por la expresión legitimatio ad causam y criticaba la de cualidad para obrar. Sostenía que esta última solía designar además otras cosas completamente distintas como el interés en obrar y, a veces, también la capacidad de representar a otros en juicio (sic) ${ }^{7}$.

Devis Echandía, al igual que Chiovenda, señala que es más conveniente mantener la denominación conocida y antigua de legitimatio ad causam o legitimación a la causa. Para él, la denominación de legitimación para obrar se presta a confusiones con el interés procesal para accionar y con el interés sustancial ${ }^{8}$.

Carnelutti, por su parte, habla de legitimación para los actos procesales, ya sea para los actos de parte, del defensor, de actos del tercero, es decir, elimina la referencia a la causa ${ }^{9}$.

Allorio utiliza únicamente el término legitimación ${ }^{10}$.

7 Chiovenda, Giuseppe, Instituciones de Derecho procesal civil, Editorial Revista de Derecho Privado, Madrid, 1948, vol. I, pág. 185.

8 Devis Echandía, Hernando, Teoria general del proceso, Editorial Universidad, Buenos Aires, 1984, t. I, pág. 298.

9 Carnelutt, Francesco, Instituciones del proceso civil, Ediciones Jurídicas Europa - América, Buenos Aires, 1973, vol. I, pág. 465 y siguientes.

10 Allorio, Enrico, Problemas de Derecho procesal, Ediciones Jurídicas Europa América, Buenos Aires, 1963, t. II, págs. 252 y 253. 
Nuestro Código Procesal Civil utiliza la denominación de legitimación para obrar (Legitimazione ad Agire), siguiendo a un importante sector de la doctrina procesalista italiana y al Código Procesal Civil y Comercial de la Nación de la República Argentina.

\section{La legitimidad para obrar no debe ser confundida con el derecho material}

Consecuente con la posición que se adopte frente al concepto de acción, tendremos la de legitimidad para obrar.

Encontramos así dos posiciones muy marcadas en la doctrina:

a) Para una corriente, la legitimidad para obrar consiste en una condición de la sentencia favorable y con ella se expresa que los derechos subjetivos privados sólo pueden hacerse valer por los titulares de la relación jurídica material contra quienes son parte de ella. Por ejemplo, en una pretensión de reinvindicación de propiedad sólo el propietario estará legitimado para plantear la pretensión (parte activa), y el poseedor no propietario del bien, para contradecirla (parte pasiva).

Esta corriente es consecuencia de ver la acción como un derecho a la tutela de un derecho realmente existente, que anteriormente hemos denominado corriente concreta (ver punto $1 .^{\circ}$ ).

Chiovenda, dentro de esta posición, considera que «para que el juez estime la demanda, no basta que considere existente el derecho, sino que es necesario que considere que éste corresponda precisamente a aquel que lo hace valer, y contra aquel contra quien es hecho valer; o sea, considere la identidad de la persona del actor con la persona en cuyo favor está la ley (legitimación activa), y la identidad de la persona del demandado con la persona contra quien se dirige la voluntad de la ley (legitimación pasiva). En la mayoría de los casos, la cuestión de la pertenencia de un derecho y de 
una acción se confunde con la cuestión de la existencia del derecho y de la acción»" ${ }^{11}$.

b) Para otra corriente, para que exista legitimidad para obrar activa o pasiva, no se requiere que las partes procesales sean titulares de la relación jurídica material; es decir, que en una pretensión relativa a una relación obligacional, las partes procesales deban ser realmente el acreedor y el deudor, sino que afirmen serlo, porque de otra manera significaría volver a las teorías concretas.

Explica Allorio, que «... para resolver afirmativamente el problema procesal referente a la legitimación para accionar, basta (según la regla) constatar que el actor ha deducido en juicio una relación jurídica, afirmando que él y el demandado son los sujetos de ella. Pero, para que evidentemente la demanda judicial sea reconocida fundada en el mérito, es necesario, entre otras cosas, que, de acuerdo a los resultados del proceso, la afirmación del actor acerca de la subjetividad activa y pasiva de la relación controvertida, se manifieste favorablemente. Hay que repetir hasta la saciedad que esta última indagación no es en modo alguno una indagación referente a la legitimación para accionar, sino una de las indagaciones necesarias para llegar a la decisión de la existencia de la relación sustancial (de ordinario: relación de derecho privado) controvertida» ${ }^{12}$.

Hoy día, la mayor parte de la doctrina, entre ellos Rocco, Devis Echandía, Montero Aroca, Redenti, Carnelutti y otros, mantienen esta posición.

Coincidimos con esta última corriente. La legitimidad para obrar no debe identificarse con el derecho material, porque de otra manera volveríamos a tesis ya superadas según las cuales sólo tiene derecho de acción quien es titular del derecho material controvertido y sólo puede tener la posición de demandado aquel otro sujeto titular de la relación jurídica material, lo que no es procesalmente válido. Éste es un asunto que concierne más bien a la existencia del derecho material, que el juez deberá decidir con el fondo del litigio; no es un asunto de legitimidad para obrar.

1 Chiovenda, op. cit., vol. I, págs. 185 y 186.

12 Allorio, op. cit., t. II, pág. 270. 
Como bien lo señala Rocco, «la titularidad efectiva o solamente afirmada de la relación o del estado jurídico (objeto de la providencia judicial pedida), constituye el criterio básico para la determinación de los sujetos legitimados para el ejercicio de una acción determinada... No cabe confundirla con el concepto de pertenencia o de existencia del derecho»" ${ }^{13}$.

Entendemos que esta doctrina informa el Código Procesal Civil peruano, cuando en el artículo IV del Título Preliminar establece que «el proceso se promueve sólo por iniciativa de parte, la que invocará interés y legitimidad para obrar». Sólo se exige, al plantear la pretensión, que se «invoque» la legitimidad para obrar, no que se demuestre, denotando el carácter estrictamente procesal que se le está otorgando.

En resumen, para encontrarse una persona legitimada para actuar en el proceso, sólo requerirá afirmar ser el sujeto autorizado por la ley para pretender la tutela judicial de un determinado derecho material, así como la afirmación de que la persona a quien se está demandando es aquel a quien de acuerdo a la ley deben recaer los efectos de la cosa juzgada.

\section{Legitimidad para obrar de los terceros}

Al lado de la legitimidad activa (del demandante) y pasiva (del demandado), se encuentra la legitimidad para intervenir, que es aquella que la ley establece para quienes participan en un proceso ya iniciado entre otras personas, sin haber tenido la condición inicial de demandante ni demandado.

Estamos frente al instituto procesal de la intervención de terceros, legislada en nuestro Código Procesal Civil en el artículo 97 y siguientes.

Existen diversas formas reconocidas de intervención de terceros. A veces el tercero se apersona al proceso por propia voluntad, mientras que otras es llamado para intervenir, a pedido de una de las partes o de oficio por el juez. En algunos casos el tercero interviene en orden a un interés en el resultado del proceso, sin ser titular de la relación jurídica material; en

13 Rocco, op. cit., vol. I, pág. 360. El paréntesis y su contenido es nuestro. 
otros, interviene invocando la titularidad de la relación jurídica material sobre la que van a recaer los efectos de la cosa juzgada; en otros, invoca derechos excluyentes u opuestos al de las partes; etc.

De acuerdo a las características de cada una de las formas de intervención de terceros, la ley procesal determina las personas que se encuentran legitimadas para intervenir en el proceso.

En algunos casos, como en la intervención litisconsorcial (artículo 98), el tercero pasará a sumarse al grupo de sujetos con legitimación activa o pasiva. En otros, como en la intervención coadyuvante (artículo 97), el tercero asumirá una posición de tipo secundario o menos plena, aunque, en nuestra opinión, ello no obste para que pase también a integrar la posición activa o pasiva en el proceso, según colabore con la parte demandante o la parte demandada.

\section{Legitimidad ordinaria y extraordinaria}

Suele distinguirse entre legitimidad para obrar ordinaria y extraordinaria.

La legitimidad ordinaria es la más común. Se presenta cuando el demandante afirma ser titular del derecho subjetivo cuya tutela pretende (legitimidad activa) y dirige la pretensión contra quien el propio demandante afirma ser la parte pasiva de la relación jurídica de derecho material (legitimidad pasiva). Así, por ejemplo, «A» demanda a «B» pretendiendo de éste el pago de una deuda derivada de un contrato de mutuo. Existirá legitimidad activa si «A» afirma ser el mutuante y dirige la pretensión contra «B», de quien afirma que es el mutuatario.

Nótese en el ejemplo que para que exista legitimidad activa el demandante puede o no ser realmente el mutuante: basta su afirmación de serlo. Igualmente, en lo que se refiere a la parte pasiva basta imputar al demandado la calidad de mutuatario. La existencia o inexistencia del derecho material, tal como lo hemos señalado anteriormente, es una cuestión de fondo, distinta de la legitimidad para obrar, que es una figura típicamente procesal.

La legitimidad para obrar extraordinaria no está ya referida al ejerci- 
cio de los derechos materiales por quien afirma ser su titular, sino por quien la ley autoriza a ejercitarlos a pesar de tratarse de derechos ajenos.

El caso más conocido de legitimidad extraordinaria lo constituye el contemplado por el inciso $4 .^{\circ}$ del artículo 1219 del Código Civil. Esta norma otorga al acreedor el derecho de ejercer los derechos de su deudor, sea en vía de acción o para asumir su defensa. La doctrina civilista denomina acción subrogatoria u oblícua a la pretensión que formula en estos casos el acreedor.

Es así que el acreedor frente a un deudor negligente e insolvente tiene el derecho de cobrar judicialmente el crédito de su deudor, a fin de conservar e incrementar el patrimonio de su deudor; de no hacerlo, se verá perjudicado puesto que no se encontrará en aptitud de cobrar su propio crédito. También el acreedor podrá actuar colaborando en la defensa de su deudor, en caso que éste recurra a los estrados judiciales para cobrar su crédito. Por ejemplo, «A» es acreedor de «B» $y$ «B» es a su vez acreedor de «C». Encontrándose exigible el crédito entre $« B » y » C »$, si $« B »$ no despliega actividad alguna en orden a cobrar su crédito, el derecho autoriza $a$ «A» a ejercitar el cobro del crédito directamente a «C», o a colaborar en la defensa de «B» si éste último hubiera iniciado el proceso judicial contra «C». Todo ello en orden a incrementar el patrimonio de «B»y así «A» poder cobrar su crédito.

El legislador procesal civil denomina estos casos en el artículo $60 \mathrm{del}$ Código como de «sustitución procesal». Al efecto, señala que «en el caso previsto en el inciso $4 .^{\circ}$ del artículo 1219 del Código Civil y en los demás que la ley permita, una persona puede iniciar un proceso o coadyuvar la defensa del ya iniciado cuando tenga interés en su resultado, sin necesidad de acreditar derecho propio o interés directo en la sentencia discutida».

Rocco, Redenti y Devis Echandía, entre otros autores, han cuestionado el concepto de sustitución procesal sosteniendo que es preferible hablar de legitimidad extraordinaria, con lo que coincidimos.

Señala Rocco, que «la legitimación activa o pasiva de los sujetos no titulares de relaciones jurídicas objeto de la acción se ha tratado de explicar por algunos mediante el concepto de sustitución procesal, instituto análogo al del derecho privado, en que se admite a alguien a ejercitar derechos aje- 
nos en nombre propio... si por ejercicio del derecho ajeno en nombre propio queremos referirnos al derecho sustancial, entonces ese ejercicio por parte del sustituto procesal no se verifica, ya que él, a lo más, ejercitaría la acción ajena, siempre que se admita, con la doctrina unánime, que el derecho de acción no es un poder o un aspecto del derecho sustancial, o una facultad comprendida en el derecho material, sino un derecho separado, distinto y autónomo del derecho sustancial... es mucho más simple y mucho más consecuente reconocer que en tales casos se tiene, no el ejercicio de un derecho de acción ajena en nombre propio, sino el ejercicio de un derecho de acción propio, y por tanto, en nombre propio, que tiene por objeto una relación jurídica ajena» ${ }^{14}$.

En efecto, desde el momento en que la ley autoriza a un tercero, que no es titular del derecho o de la relación jurídica material, a ejercitar los derechos de otro, si bien desde el punto de vista del derecho material se trata de un derecho ajeno, desde el punto de vista del derecho procesal está legitimado para obrar y se trata de un derecho procesal propio. De allí que si bien podría resultar correcto el concepto de sustitución dentro del derecho privado, no lo es desde el punto de vista del derecho procesal.

Además del caso previsto en el inciso $4 .^{\circ}$ del artículo 1219 del Código Civil, existen otros supuestos en los que también se presenta la legitimidad extraordinaria. Entre otros, podemos señalar los siguientes:

a) Cuando el acreedor prendario pretende cobrar judicialmente los intereses del crédito u otras prestaciones periódicas del crédito prendado (artículo 1086 del Código Civil) o el capital e intereses del crédito de suma de dinero prendado (artículo 1088 del Código Civil).

b) Cuando el transferente de un bien es llamado al proceso de evicción a solicitud del adquirente (artículos 1498 y 1499 del Código Civil).

c) En la intervención coadyuvante de tercero prevista en el artículo 97 del Código Procesal Civil. En estos casos la ley autoriza a intervenir en un proceso en trámite que se sigue entre otros sujetos, a un tercero que tiene con una de las partes una relación jurídica sustancial a la que no se deben

14 Rocco, op. cit., vol. l, págs. 364 y 365. 
extender los efectos de la sentencia, pero que podrá ser afectada desfavorablemente si dicha parte es vencida.

Si bien en la intervención coadyuvante el tercero simplemente es un colaborador de una de las partes, y su intervención en el proceso es de tipo secundario, la ley, sin embargo, otorga a dicho tercero legitimidad para obrar, que será activa o pasiva según que la colaboración sea a la parte demandante o a la parte demandada.

d) Cuando la ley autoriza el ejercicio de los derechos procesales al simple interesado, que no es el titular de la relación jurídica material o a quien no corresponde el estado jurídico sobre el que recaerá la decisión judicial. Se trata de un interés que se presenta como algo menor al derecho subjetivo ${ }^{15}$.

En nuestra legislación encontramos muchos casos en los que el simple interesado es autorizado para plantear pretensiones o ejercer derechos dentro del proceso. Así, en el Código Civil, el artículo 47 permite a quien invoca legítimo interés en los negocios o asuntos del desaparecido, a solicitar el nombramiento de curador interino; el artículo 49 autoriza a quien tiene legítimo interés, a solicitar la declaración judicial de ausencia; el artículo 63 hace lo propio respecto de cualquier interesado en orden a solicitar judicialmente la declaración de muerte presunta; el artículo 129 confiere el derecho a solicitar judicialmente la afectación de los bienes de una fundación no inscrita a otra fundación, a quien tiene legítimo interés; el artículo 220 autoriza a alegar la nulidad de un acto jurídico a quienes tienen interés en dicha nulidad; el artículo 275 atribuye a quienes tienen interés legítimo y actual, el derecho a demandar la nulidad del matrimonio; el artículo 1999 permite a quien tiene un legítimo interés, a alegar la suspensión y la interrupción de la prescripción extintiva; etc. Igualmente, el Código Procesal Civil hace lo propio en el artículo 790 autorizando al interesado a solicitar la declaración de desaparición, ausencia o de muerte presunta; en el artículo 830, para solicitar el inicio del proceso sucesorio; etc.

e) Cuando la ley autoriza al Ministerio Público a actuar como parte o como tercero con interés. El Ministerio Público actúa en estos casos en de-

15 Montero Aroca y otros, op. cit., t. II, pág. 38. 
fensa de los intereses de la comunidad, de la legalidad o de la recta administración de justicia.

El Ministerio Público se encuentra exonerado de invocar legitimidad para obrar, tal como lo señala el artículo IV del Título Preliminar del Código Procesal Civil, lo que no significa que sea ajeno a la categoría procesal de la legitimidad. Ello se debe a que la concesión de legitimidad para obrar al Ministerio Público no supone atribución de derechos subjetivos materiales, sino simplemente la posibilidad de realizar el proceso sin pedir para él mismo $^{16}$.

Existen innumerables casos en nuestra legislación que otorgan legitimación para obrar al Ministerio Público. Como simples ejemplos citamos los siguientes: En el Código Civil, el artículo 47 (designación de curador interino del desaparecido), artículo 49 (declaración judicial de ausencia), artículo 63 (declaración de muerte presunta), artículo 96 (solicitud de disolución de asociación), artículo 108 (ampliación o modificación de fines de la fundación), artículo 120 (solicitud de disolución del comité), artículo 220 (nulidad de acto jurídico), artículo 256 (oposición al matrimonio), artículo 275 (nulidad del matrimonio), artículo 460 (nombramiento de curador especial para los hijos), artículo 512 (discernimiento de cargo de tutor), artículo 514 (providencias para el cuidado del menor y sus bienes), artículo 516 (impugnación del nombramiento de tutor), artículos 583, 587 y 588 (interdicción del incapaz mayor de edad), artículo 599 (administración de bienes y nombramiento de curador de bienes), artículo 622 (formación del consejo de familia), etc. En el Código Procesal Civil, el artículo 481 (separación de cuerpos o divorcio por causal), artículo 574 (separación convencional y divorcio ulterior), artículo 759 (procesos no contenciosos), artículo 781 (adopción), artículo 830 (proceso sucesorio), etc.

En cuanto a legitimidad se refiere, el Ministerio Público puede actuar en el proceso civil ya sea como parte (demandante o demandada) o como tercero con interés, según lo precisan los incisos $1 .^{\circ}$ y $2 .^{\circ}$ del artículo 113 del Código Procesal Civil.

f) Cuando actúa el procurador oficioso. El artículo 81 del Código

i6 Montero Aroca y otros, op. cit., t. II, pág. 39. 
Procesal Civil regula esta figura, que consiste en que una persona puede comparecer judicialmente en nombre de otra de quien no tiene representación judicial, debido a que la persona por quien se comparece se encuentra impedida de hacerlo por sí misma, está ausente del país, tiene razones de fundado temor o amenaza, se trata de una situación de emergencia o de eminente peligro, o por otra causa análoga.

El artículo IV del Título Preliminar del Código Procesal Civil exonera al procurador oficioso, en la misma forma que en el caso anterior, de la obligación de invocar legitimidad para obrar. Ello se debe a que el procurador oficioso actúa en una suerte de gestor de negocios procesal, en orden a la tutela de derechos ajenos frente a una situación excepcional y animado por una motivación altruista.

g) Cuando se actúa en defensa de intereses difusos. El artículo 82 del Código Procesal Civil define el interés difuso como aquel cuya titularidad corresponde a un conjunto indeterminado de personas, respecto de bienes de inestimable valor patrimonial, tales como la defensa del medio ambiente, de bienes o valores culturales o históricos, o del consumidor.

Esta norma autoriza a promover el proceso o intervenir en él, al Ministerio Público y a las asociaciones o instituciones sin fines de lucro que según la ley o el criterio del juez están legitimados para ello.

El artículo IV del Título Preliminar del Código Procesal Civil, nuevamente exonera, esta vez a quien promueve el proceso en defensa de intereses difusos, de invocar legitimidad para obrar. La razón es la misma que hemos expuesto respecto del Ministerio Público, en tanto que la ley, al otorgar legitimidad en defensa de intereses difusos, no está atribuyendo derechos subjetivos materiales a las personas o entidades respectivas, sino la posibilidad de actuar procesalmente sin pedir nada para ellas.

\section{Legitimatio ad causam y legitimatio ad processum}

La doctrina clásica opuso el concepto de legitimatio ad causam al de legitimatio ad processum, para referirse a esta última como el presupuesto procesal de la capacidad jurídica de las partes. 
La capacidad procesal de las partes constituye un verdadero presupuesto procesal, de manera que si falta, el proceso es inválido.

La legitimidad ad causam o legitimidad para obrar no constituye un presupuesto procesal, sino un requisito para que el juez se encuentre en aptitud de resolver el fondo de la litis. Su ausencia no invalida el proceso, sino que da lugar a una sentencia inhibitoria del juez respecto de la cuestión de fondo.

Existe una marcada tendencia en la doctrina para dejar de lado el término legitimatio ad processum y referirse únicamente a la capacidad de las partes, utilizando su propia terminología. De esta manera se evita la confusión con la legitimatio ad causam o legitimidad para obrar ${ }^{17}$.

\section{La legitimidad para obrar como presupuesto de la pretensión y de la contradicción}

La legitimidad para obrar constituye un presupuesto de la pretensión y de la contradicción, no así una condición ni elemento de la acción.

Resulta conveniente abandonar la antigua atribución de condición de la acción para la legitimidad para obrar, y considerar, más bien, que ésta constituye un presupuesto de la pretensión y de la contradicción para que el juez se encuentre en la posibilidad de pronunciar sentencia de fondo o de mérito, independientemente de que, al examinar el derecho, pronuncie o no una sentencia favorable o desfavorable al demandante.

Como bien lo ha expresado Devis Echandía, la legitimación no condiciona ni limita en ningún sentido la acción, ni su falta impide su válido y eficaz ejercicio. Si así no fuera, no podría ejercitar la acción quien no estuviera legitimado, y como esto por regla general sólo se conoce cuando se dicta la sentencia, se tendría el absurdo y contradictorio resultado que parecería que el demandante no tiene acción sino después que ella ha producido todos sus efectos jurídicos. Agrega el referido autor, que la legitimidad

17 Devis Echandia adopta esta posición en op. cit., t. I, pág. 293. 
para obrar «es un presupuesto de la pretensión contenida en la demanda y de la oposición que a aquélla formula el demandado, para que sea posible la sentencia de fondo, que resuelva sobre ellas... Estar legitimado en la causa significa tener derecho a exigir que se resuelva sobre las peticiones formuladas en la demanda, es decir, sobre la existencia o inexistencia del derecho material pretendido, ya por medio de sentencia favorable o desfavorable» ${ }^{18}$.

El juez sólo podrá pronunciarse sobre el fondo si previamente ha establecido la existencia de la legitimidad para obrar, tanto activa como pasiva. En caso de advertir que no existe la legitimidad, el juez se limitará a un pronunciamiento inhibitorio sobre el fondo, es decir, no se encontrará en aptitud de examinar ni decidir sobre la existencia o inexistencia del derecho material cuya tutela se ha pretendido.

\section{Oportunidad procesal para determinar la existencia de la legitimidad para obrar}

En el proceso de cognición ${ }^{19}$, la oportunidad en la que el juez establece ordinariamente la existencia o inexistencia de la legitimidad para obrar, es el momento en que pronuncia la sentencia definitiva y como aspecto previo a la determinación de la existencia del derecho sustantivo cuya tutela es objeto de la pretensión.

Cabe recordar que en el proceso de cognición la declaración judicial de certeza se produce en la sentencia definitiva. La pretensión, al ser exhi-

18 Devis Echandía, op. cit., t. I, págs. 289, 290 y 291.

19 El proceso de cognición es también conocido en la doctrina procesal con la denominación de proceso de conocimiento o de proceso declarativo genérico. Persigue la «declaración de un derecho o responsabilidad o... la constitución de una relación jurídica... el juez regula un conflicto singular de intereses, y determina quién tiene el derecho, es decir, el juez es quien ius dicit» (Devis Echandía, op. cit., t. I, pag. 166). En esta clase de proceso la declaración de certeza la efectúa el juez en la sentencia. No debe llevar a confusión el concepto de proceso de conocimiento que estamos tratando, con el procedimiento tipo que el Código Procesal Civil nacional titula «proceso de conocimiento» al lado de otros procedimientos tipos como son el proceso abreviado y el proceso sumarísimo. 
bida en la demanda, sólo implica la afirmación de un derecho cuya tutela se persigue, y recién será en la sentencia que el juez se encuentre en aptitud de determinar la real existencia de tal derecho. Lo propio sucede con la legitimidad para obrar.

Nuestro código procesal, con técnica y acierto, en el artículo IV del Título Preliminar exige que el demandante al plantear la demanda «invoque» legitimidad para obrar, sin reclamar en ese momento mayores comprobaciones.

Sin embargo, los códigos más modernos autorizan al juez, en aras de una efectiva economía procesal, a rechazar liminarmente el trámite de una demanda cuando resulta manifiesta la falta de legitimidad para obrar. Ello evita una inútil actividad procesal. De otra manera habría que esperar el despliegue de todo un proceso para llegar finalmente a la sentencia definitiva y en ese momento el juez poder advertir la imposibilidad de entrar al análisis de mérito por la carcncia de la legitimidad, a pesar de que desde el inicio era clara esta situación.

Nuestro código sigue esta tendencia, permitiendo al juez que declare improcedente la demanda cuando el demandante carece evidentemente de legitimidad para obrar. Así lo establece en el inciso $1 .^{\circ}$ del artículo 427 y la parte final del mismo.

En caso de que el juez no lo advierta inicialmente, el demandado podrá denunciar tal carencia en vía de excepción, según lo prevé el inciso $6 .^{\circ}$ del artículo 446 del código acotado. La falta de legitimidad para obrar, a proponerse a través de una excepción, podrá basarse en la falta de legitimidad para obrar del demandante o del demandado.

Si el juez accede a dicha excepción, el efecto será el de anular todo lo actuado y dar por concluido el proceso, si se trata de falta de legitimidad para obrar del demandante (inciso $5 .^{\circ}$ del artículo 451 ), y el de suspender el proceso hasta que el demandante establezca la relación jurídica procesal entre las personas que el auto resolutorio ordene y dentro del plazo que éste fije, si se trata de falta de legitimidad para obrar del demandado. En este último caso, de no subsanarse el defecto por el demandante dentro del plazo fijado, concluirá el proceso (inciso $4 .^{\circ}$ del artículo 451 ). 
Ahora bien, nuestro código no exige como requisito para plantear una excepción de esta naturaleza, el que la falta de legitimidad sea «evidente» o «manifiesta», como sí lo hace cuando autoriza al juez a declarar la improcedencia de plano de la demanda por la carencia de legitimidad para obrar.

Códigos como el de Procedimientos en Materia Civil y Comercial de la Nación de la República Argentina, y el uruguayo, sólo permiten que se debata la falta de legitimidad en vía de excepción previa, si aquélla resulta manifiesta; en caso contrario, el juez deberá considerarla recién en la sentencia definitiva. Asevera De Santo, comentando el derecho procesal argentino, que no se justifica la apertura de esta excepción a prueba, puesto que si se hace es porque la falta de legitimidad no aparece manifiesta. Considera que la falta de legitimidad debe reputarse como manifiesta cuando puede declararse sin otro trámite que el traslado de la excepción a la actora y sobre la base de los elementos de juicio inicialmente incorporados a la causa como son las manifestaciones de las partes, documentos, etc ${ }^{20}$.

Aun cuando, repetimos, nuestro código no ha establecido como requisito para la procedencia de la excepción de falta de legitimidad para obrar el que sea «evidente» 0 «manifiesta», y, por lo tanto, no podemos efectuar distingos donde la propia ley no lo hace, empero, consideramos que el juez debe actuar con especial cuidado frente a esta excepción, de manera de no perder de vista el carácter procesal que tiene la legitimidad para obrar y evitar que, so pretexto de resolver sobre la carencia de la misma, esté decidiendo sobre la existencia o inexistencia del derecho sustancial cuya tutela es objeto de la pretensión (ver punto $4 .^{\circ}$ ). Ello sólo corresponderá hacerlo en la sentencia definitiva de mérito. Lo regular es que la carencia de legitimidad surja del propio planteamiento de la pretensión o de la documentación aportada inicialmente al proceso, y que el juez para amparar la excepción no requiera efectuar mayores indagaciones probatorias, pero no siempre es así.

En efecto, razones de economía procesal hacen conveniente que se permita, en algunos casos, por la vía de la excepción, la subsanación de defectos en la legitimidad para obrar o determinar su carencia, de manera que

20 De SANto, Víctor, Diccionario de Derecho procesal, Editorial Universidad, Buenos Aires, 1991, pág. 136. 
el proceso no avance innecesariamente hasta la decisión final para obtener un resultado inhibitorio del juez respecto al mérito o la anulación de lo actuado o el mandato de subsanación tardía de los defectos en la legitimidad para obrar.

Dentro de la actual estructura procedimental del proceso civil nacional, la oportunidad previa para determinar la existencia de una relación jurídica procesal válida o el otorgamiento de plazos que permitan la subsanación de defectos subsanables o la anulación del proceso por defectos insubsanables, se realiza por el juez en un acto expreso de saneamiento del proceso, oportunidad en que decide sobre las excepciones y defensas previas planteadas (artículos 465 y 449).

Resulta importante destacar ciertos supuestos en los que la determinación de la legitimidad para obrar es preciso establecerla con prontitud. Tenemos el caso de la litis consorcio necesaria (artículo 93), en que deben participar en el proceso todas las personas a quienes afectará de manera uniforme la sentencia, puesto que de lo contrario no existirá decisión final de mérito válida. Así, si la pretensión pedida es la nulidad de un contrato, la relación jurídica procesal deberá entablarse necesariamente con todos los sujetos que son parte en el contrato; de lo contrario, la cosa juzgada no los alcanzará y cualquier decisión judicial será ineficaz. El artículo 95 del Código Procesal Civil autoriza al juez a integrar de oficio la relación procesal si no ha quedado correctamente establecida en base al planteamiento efectuado por las partes. También procederá en estos casos que, a raíz del planteamiento de una excepción de falta de legitimidad para obrar, se dé lugar a la subsanación de los defectos señalados.

Se hace igualmente necesaria una pronta determinación sobre la legitimidad en aquellos casos en que deben incorporarse a nuevos sujetos al proceso, ya sea por sucesión procesal en los supuestos del artículo 108 del Código Procesal Civil (fallecimiento de una de las partes durante el proceso, extinción o fusión de una persona jurídica, etc.), o en ciertas intervenciones de terceros (artículo 101). Asimismo, en todos aquellos casos en que el juez deba efectuar la determinación de certeza de derechos materiales en momento distinto a la sentencia.

Por otra parte, y en orden a la providencia pedida, existen procesos en los que el juez debe efectuar una apreciación liminar de la legitimidad para 
obrar. Es el caso de los procesos ejecutivos y, en general, de todos los procesos de ejecución. En estos casos el juez accede de inmediato a la providencia pedida en la demanda mediante un pronunciamiento sobre el fondo, ante la presencia de una declaración cierta del derecho material contenida en un «título» (artículo 688 del Código Procesal Civil). Al efecto, el artículo 689 precisa que procede dar la ejecución cuando la obligación contenida en el título es cierta, expresa y exigible. Dado que el juez efectúa un pronunciamiento en forma liminar sobre el fondo de lo pedido, en ese mismo momento determina el cumplimiento del presupuesto de la legitimidad para obrar activa y pasiva que ha sido afirmada en la demanda en base a un título que contiene una relación jurídica cierta.

\section{Diferencia con el interés para obrar}

Es conveniente efectuar el deslinde de los conceptos de legitimidad para obrar con el de interés para obrar, con el objeto de evitar frecuentes confusiones prácticas.

Ambos son requisitos previos para que el juez pueda pronunciar una sentencia de mérito.

La legitimidad para obrar está referida a la presencia en el proceso de aquellas personas autorizadas por la ley en orden a la eficacia del objeto perseguido por el mismo. El interés para obrar alude, más bien, a la necesidad de obtener la tutela jurisdiccional respecto de un interés sustancial determinado.

El interés para obrar es un interés de tipo procesal que se distingue del interés sustancial, estando vinculado este último con el derecho discutido en el proceso, o el derecho cuya declaración se pretende.

El interés procesal denominado interés para obrar, existirá en la medida en que la providencia jurisdiccional requerida esté dirigida a producir una utilidad sobre el actor o el demandado, o exista la necesidad de recurrir ante los organos de la jurisdicción para que se tutele un derecho.

Recojamos las palabras del maestro Carnelutti sobre la distinción de 
marras: «el interés para obrar supone, por tanto, la legitimación, mientras ésta no implica el interés; lógicamente, el problema de la legitimación precede al problema del interés para obrar. El interés... se refiere, no a la pertenencia, sino al ejercicio de la acción; así, se distingue el uno de la otra, aclarando que la legitimación, lo mismo que la capacidad, se refiere al modo de ser subjetivo, mientras que el interés concierne al modo de ser objetivo (causal) del acto» ${ }^{21}$.

La legitimidad para obrar y el interés para obrar han sido confundidos en muchas ocasiones, especialmente en el tratamiento práctico de ellas por parte de jueces y abogados a partir de la defectuosa formulación legal del artículo VI del Título Preliminar del Código Civil (y su antecedente, el artículo IV del Título Preliminar del Código Civil de 1936), que hace referencia a un legítimo interés económico o moral como requisito para ejercitar o contestar una acción. Algunos comentaristas del Código Civil han interpretado, incluso, que dicha norma está referida a la legitimidad para obrar o al interés sustancial.

Esperamos que la aplicación del nuevo Código Procesal Civil lleve consigo un tratamiento cabal de ambas figuras.

21 Carnelutti, Francesco, Derecho procesal civil y penal, t. I, pág. 132, citado por Monroy Cabra, Marco Gerardo, en Principios de Derecho procesal civil, Editorial Temis Librería, Bogotá, 1979, pág. 190. 